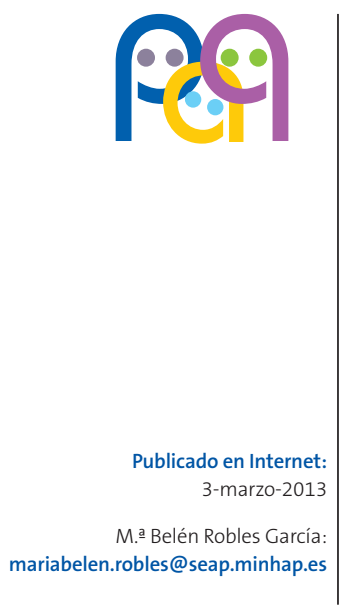

Revisión

\title{
Ellos también viajan
}

\author{
M. B. Robles García
}

\section{Certificate in Travel Health ${ }^{\circledR}$. Pediatría y Medicina Preventiva y Salud Pública.} Jefa de Servicio de Sanidad Exterior. Asturias. España.

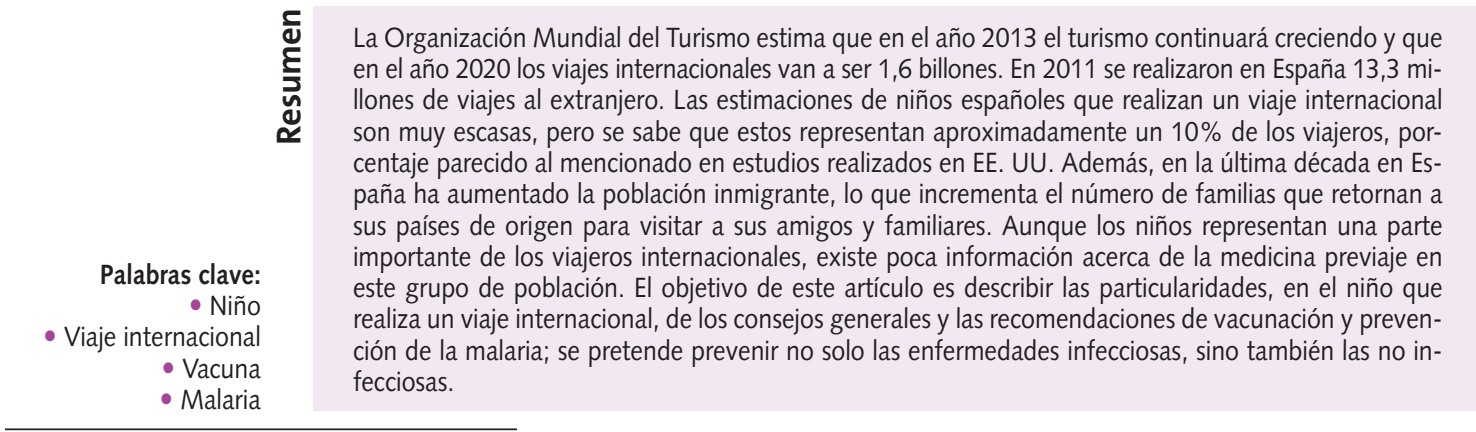

\section{Child Travellers Count}

The World Tourism Organization estimates that in 2013 tourism will continue growing and that in 2020 there will be 1.6 billion international trips taken. In 2011, there were 13.3 million trips taken abroad in Spain. There are very few figures for the number of international trips taken by Spanish children, but it is known that they form about $10 \%$ of travellers, a similar percentage to that found in US studies. Furthermore, during the last decade the immigrant population of Spain has grown, increasing the number of families returning to their home country to visit friends and relations. Although children make up a significant proportion of international travellers there is little information on pre-travel medicine for this group. The aim of this article is to describe the particularities of general advice, vaccination recommendations and malaria prevention for child international travellers, with the purpose of both infectious and non-infectious disease prevention.

\section{INTRODUCCIÓN}

La Organización Mundial del Turismo estima que en el año 2013 el turismo continuará creciendo y que en el 2020 los viajes internacionales van a ser 1,6 billones $^{1,2}$ (visión del turismo en el año 2020: www.unwto.org/facts/menu.html). Los residentes en España, durante el año 2011, realizaron 13,3 millones de viajes al extranjero acumulando tres años consecutivos de aumentos ${ }^{3}$. Las estimaciones de los niños españoles que realizan un viaje internacional son muy escasas, pero se sabe que representan aproximadamente un $10 \%$ de los viajeros, porcentaje parecido al mencionado en estudios realizados en EE. UU. ${ }^{4,5}$. Además, en la última década en España se ha incrementado la población inmigrante, lo que aumenta el número de familias que retornan a sus países de origen para visitar a 
sus amigos y familiares (visiting relatives and friends [VRF] $)^{6-8}$. Aunque los niños representan una parte importante de los viajeros internacionales, existe poca información de la medicina previaje en este grupo de población. El objetivo de este artículo es describir las particularidades, en el niño que realiza un viaje internacional, de los consejos generales y las recomendaciones de vacunación y prevención de la malaria; se pretende prevenir no solo las enfermedades infecciosas sino también las no infecciosas.

\section{LA CONSULTA PREVIA AL VIAJE INTERNACIONAL}

La consulta previa a la realización del viaje en España se lleva a cabo en los Centros de Vacunación Internacional dependientes del Ministerio de Sanidad, Política Social e Igualdad, y algunos de las comunidades autónomas ${ }^{9}$.

\section{Objetivos}

- Ayudar a los padres o al tutor legal a valorar el riesgo/beneficio de las recomendaciones/actuaciones.

- Conseguir que los niños tengan un viaje saludable, reduciendo los riesgos relacionados con dicho viaje.

- Aconsejar de manera especial a aquellos niños con problemas médicos.

- No aconsejar exclusivamente sobre vacunaciones y quimioprofilaxis contra la malaria.

\section{Claves durante la consulta}

- Contar con el tiempo suficiente para plantear preguntas y dudas, y para que se comprenda la información.

- Advertir e informar a los padres de los efectos secundarios de las vacunas y de la quimioprofilaxis recomendadas, y del tiempo en que pueden aparecer.

- Se debe valorar el retrasar el viaje en función de la edad del niño, del tipo de viaje, etc. Por lo ge- neral, y a diferencia de la consulta previaje de los adultos, en el caso de niños que van a viajar, los padres acuden con mucho tiempo de antelación exclusivamente para pedir consejo.

- Informar sobre consejos generales, vacunas sistemáticas, vacunas específicas y prevención de la malaria y de otras enfermedades transmitidas por artrópodos.

- Cuándo acudir: al menos un mes y medio antes del viaje $e^{10,11}$.

\section{La historia clínica}

Las consecuencias fatales de muchas enfermedades adquiridas durante un viaje internacional hacen que la historia clínica pediátrica sea una de las partes más importantes de la consulta previaje ${ }^{12}$. El médico especialista en Medicina del viajero no tiene acceso a la historia clínica del niño, a no ser que contacte con su pediatra o los padres aporten los informes clínicos.

\section{CONSEJOS GENERALES; VIAJAR SEGURO CON NIÑOS}

\section{Precauciones con agua y alimentos (diarrea del viajero, hepatitis A, fiebre tifoidea, cólera, etc.)}

- Comer los alimentos siempre bien cocinados y evitar consumir pescado, marisco u otros alimentos crudos.

- Beber agua embotellada y no tomar hielo si no ha sido preparado con agua segura.

- Evitar la comida de los vendedores calleje$\operatorname{ros}^{13,14}$

Protección contra mosquitos, garrapatas, piojos, pulgas (fiebre amarilla, malaria, dengue, encefalitis centroeuropea, encefalitis japonesa, ricketsiosis, etc.)

- La ropa debe cubrir la mayor parte del cuerpo (se debe llevar manga y pantalón largos, calcetines, zapato cerrado, gorra) y ser de colores claros. Debe evitarse usar sandalias, colores oscuros o chillones y colonias. 
- El alojamiento debe hacerse en una habitación con aire acondicionado o ventilador.

- Hay que aplicar repelente de insectos varias veces al día, veinte minutos después de la crema solar, sobre la piel expuesta al aire (evitando heridas y mucosas), pero no en las manos, debajo de la ropa ni en muñecos (Tabla 1). El efecto secundario más frecuente es la dermatitis. El repelente no se lo debe aplicar el niño, nunca deberemos dejar el repelente a su alcance ${ }^{15,16}$.

- Deberemos aplicar insecticida también sobre la ropa y las mosquiteras. La permetrina es un insecticida muy eficaz en la prevención de picaduras por artrópodos ${ }^{15,16}$ :

- Impregnar la ropa con permetrina (solución al 0,5\%): se debe pulverizar la ropa durante 30-45 segundos y dejarla secar, al menos, durante un periodo de dos a cuatro horas antes de ponérsela al niño.

- Impregnar las mosquiteras (que tendrán una malla inferior a 1,5 $\mathrm{mm}$ ) de la cama y la cuna con permetrina (solución al 13,3\%). Existen mosquiteras ya previamente tratadas.

\section{Otros consejos}

- Identificación y seguro médico:

- El niño tiene que llevar una tarjeta identificativa con su nombre, apellidos, teléfono, dirección, etc., sujeta en su ropa.

- Al igual que los adultos, los niños tienen que viajar con un seguro médico que incluya evacuación ${ }^{14,17,18}$ en el caso de que sea necesaria.

- Debemos conocer los centros sanitarios de referencia en el área visitada.

- Si un niño viaja solo con uno de sus progenitores, debe llevar un consentimiento firmado por el otro progenitor.
- Accidentes de tráfico:

- Es la causa más frecuente de muerte en niños que viajan ${ }^{19}$.

- Es obligatorio utilizar casco cuando se va en moto.

- Hay que utilizar siempre los cinturones de seguridad en los coches.

- Viaje en avión:

- Viajar en avión es similar a estar aproximadamente a $2500 \mathrm{~m}$ sobre el nivel del mar. No existen datos que sugieran un mayor riesgo de hipoxia en niños pequeños, a no ser que tengan una patología cardiopulmonar ${ }^{20}$.

- No se recomienda sedación ${ }^{12}$.

- El niño no debe ir sentado en la fila del pasillo, ya que existe riesgo de caídas de equipajes.

- Al aterrizar y al despegar el avión, puede ocurrir que sufra dolor de oídos, por lo que se le debe dar líquido para beber (lactancia materna, biberón). Los niños mayores pueden mascar chicle ${ }^{14,21,22}$.

- Al llegar al destino, debemos intentar regular el sueño del niño, procurando que sea similar al de los adultos $14,23,24$.

- Exposición al sol:

- Utilizar protección solar de, al menos, factor 15 (mejor si es protección extrema), que proteja contra radiaciones ultravioleta $A$ (UVA) y $B(U V B)$, además de gorro y gafas de sol ${ }^{14}$.

- Contacto con animales:

- Evitar el contacto con animales ${ }^{14,25}$.

- Enseñar al niño que si le muerde un animal debe "contarlo" a un adulto.

- Viaje en cruceros:

- Hay un riesgo mayor de infecciones por los virus influenza y los de transmisión gastrointestinal ${ }^{26,27}$.

\begin{tabular}{|l|l|}
\hline \multicolumn{1}{|c|}{ Tabla 1. Principio activo del repelente y edad de inicio de su aplicación } \\
\hline \multicolumn{1}{|c|}{ Principio activo repelente y concentración } & \multicolumn{1}{c|}{ Edad de inicio de aplicación } \\
\hline 1. DEET 30\% & $>2$ meses \\
\hline 2. Icaridina 20\% (Autan-Activo ${ }^{\circ}$ ) & $>2$ años \\
\hline 3. Extracto de eucalipto-limón $20 \%$ (Corymbia citriodora) & $>3$ años \\
\hline
\end{tabular}

DEET: N,N-Dietil-meta-toluamida. 
- Diarrea del viajero:

- Es necesaria la rehidratación oral ${ }^{15}$ cuando la sufra. Se debe valorar la tolerancia oral tan pronto como aparezca la gastroenteritis. No está recomendada la dieta absolu$\mathrm{ta}^{13,14}$. Si no cede, las opciones terapéuticas son muy escasas ${ }^{13,28}$ : para niños entre 6 meses y 12 años, el antibiótico de elección es la azitromicina (10 mg/kg/día) durante tres días; las fluoroquinolonas no se deben recomendar hasta los 18 años de edad. Algunos autores promueven su indicación debido a su eficacia y porque solo se administran entre uno y tres días ${ }^{29}$; la rifaximina no está autorizada ${ }^{30}$.

- No se debe recomendar antiperistálticos intestinales en niños muy pequeños.

- Las sales de bismuto están contraindicadas (contienen salicilatos) $^{14}$.

- Mal de altura ${ }^{31}$ :

- Los niños son más susceptibles a padecerlo.

- Los síntomas y signos del mal de altura son malestar general, náuseas, dolor de cabeza, fatiga y pérdida de apetito. El diagnóstico del mal de altura, al igual que en otras patologías, es más difícil de reconocer en niños.

- Hay tres reglas que deben seguirse: 1) conocer los síntomas; 2) nunca ascender si se presenta algún síntoma, y 3) descender si se presenta algún síntoma.

- Cinetosis:

- Valorar recomendar bloqueantes colinérgicos: dimenhidrinato en dosis de $5 \mathrm{mg} / \mathrm{kg} /$ día, cada 8-12 horas, una hora antes del via$\mathrm{je}^{32}$.

- Adolescentes ${ }^{33}$ :

- Consejos para prevención de enfermedades de transmisión sexual: virus de la inmunodeficiencia humana $(\mathrm{VIH})$, gonorrea, sífilis, etc.; utilizar siempre preservativos.

- Evitar las salidas nocturnas.

- No se deben combinar los deportes acuáticos con el alcohol.
- Otros consejos ${ }^{14}$ :

- El niño debe saber nadar.

- No debe bañarse en aguas estancadas.

- Hay que hacer caso a las señalizaciones de peligro (por ejemplo, señales que especifican no bañarse en determinadas zonas, o que advierten de la existencia de animales peligrosos, etc.).

- No andar descalzo, ya que muchas parasitosis penetran por la piel (infestación por Larva migrans, tricuriasis, strongyloidiasis...). El calzado debe ser fresco y cómodo.

- No poner a secar la ropa sobre el suelo.

- Realizar el alojamiento en un lugar seguro.

\section{Botiquín pediátrico}

En la Tabla 2 se describen los componentes mínimos del botiquín pediátrico que hay que llevar en un viaje internacional ${ }^{14}$.

\section{VACUNAS SISTEMÁTICAS; CALENDARIO VACUNAL INFANTIL}

La vacunación sistemática del niño se realiza fundamentalmente durante los primeros dos años de vida ${ }^{34}$.

El niño que realiza un viaje internacional debe tener al día las vacunas de calendario o, al menos, la vacuna frente a difteria, tétanos y tos ferina, la de la polio, la triple vírica, la vacuna frente a Haemophilus influenzae tipo b y la del virus de la hepatitis B. En su caso, se aplicarán las pautas de vacunación acelerada recomendadas por el Comité Asesor de Vacunas de la Asociación Española de Pediatría ${ }^{34}$. Para completar los retrasos o interrupciones del calendario de vacunas, siempre se tendrán en cuenta las dosis anteriores recibidas, y se tratará de completar el número de dosis adecuado en el mínimo tiempo (manteniendo la separación necesaria entre las dosis). Una vez completadas, se continuará con el calendario vacunal establecido. 
Tabla 2. Modelo de botiquín pediátrico en un viaje internacional

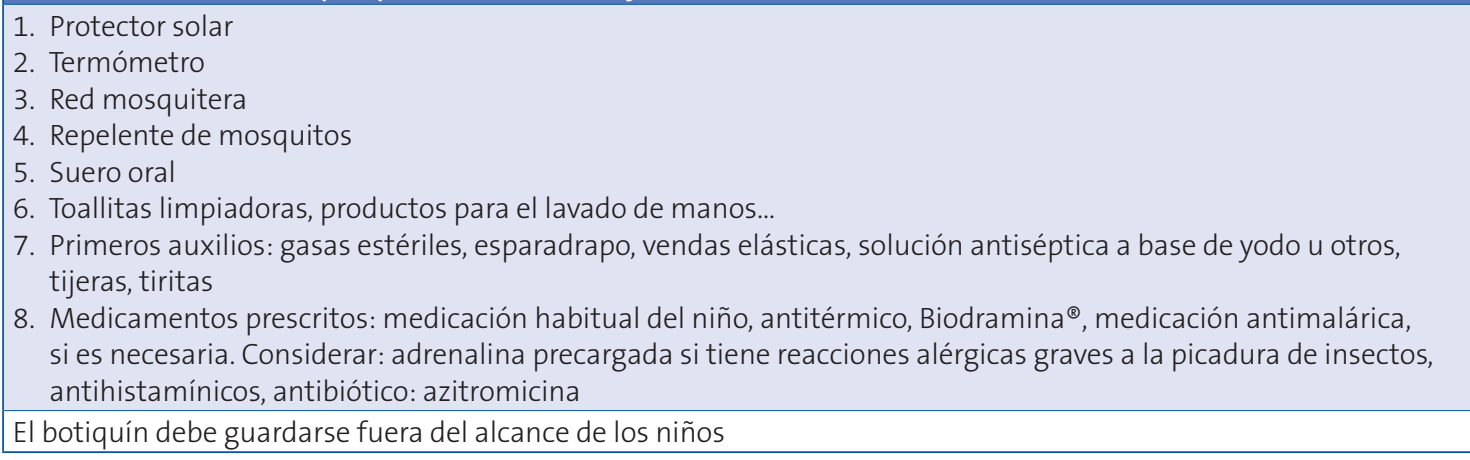

\section{Puntos clave}

- El niño que realiza un viaje internacional debe tener actualizado el calendario vacunal.

- La consulta del niño viajero es una excelente oportunidad para revisar la historia vacunal y completar dosis perdidas de vacunas.

- La interrupción o el retraso de la pauta de vacunación nunca hace necesario que se empiece de nuevo (excepto para la vacuna de tifus oral, indicada en viajes internacionales).

\section{VACUNAS ESPECÍFICAS DEL NIÑO OUE REALIZA UN VIAJE INTERNACIONAL}

En el niño viajero, de una forma similar a como se ha descrito para las vacunas de calendario, para completar los retrasos o interrupciones de las vacunas específicas siempre se tomarán en cuenta las dosis anteriores recibidas, y se tratará de completar el número de dosis adecuado en el mínimo tiempo posible antes del viaje, manteniendo la separación necesaria entre las dosis. Excepciones a esta regla son la vacuna de tifus oral (si no se toma una dosis se debe reiniciar), y la vacuna triple vírica administrada antes de los 12 meses de edad (porque después del año de vida aún se requieren dos $\left.\operatorname{dosis}^{34,35}\right)$.

\section{Fiebre amarilla}

Es una fiebre hemorrágica viral trasmitida por la picadura de mosquitos, con alta letalidad en niños. Los requerimientos internacionales de algunos países establecen la obligatoriedad, a partir de los nueve meses de vida, del Certificado Internacional de Vacunación de la fiebre amarilla para la autorización de la entrada ${ }^{36}$ en el país. La enfermedad es endémica durante todo el año en áreas predominantemente rurales de países subsaharianos de África y en América del Sur (recomendaciones de vacunación de fiebre amarilla en África 2010: http://wwwnc.cdc.gov/tra vel/yellowbook/2012/list/maps.htm; recomendaciones de vacunación de fiebre amarilla en América 2010: http://wwwnc.cdc.gov/travel/yellow book/2012/list/maps.htm). Los brotes en áreas urbanas se han multiplicado en los últimos años ${ }^{37}$.

\section{Indicaciones de vacunación en el niño que realiza un viaje internacional}

Los niños mayores de nueve meses que se dirijan a áreas endémicas o epidémicas de fiebre amarilla deberán ser vacunados, aunque dichos países no exijan el certificado de vacunación ${ }^{37}$.

\section{Consideraciones de edad: vacuna frente a la fiebre amarilla}

- Vacuna de virus vivos atenuados (cepa 17D $)^{38}$. No existe presentación infantil de la vacuna (Tabla 3). La vacuna frente a la fiebre amarilla en niños, por lo común, se considera inocua y eficaz. Sin embargo, en muy raras ocasiones, aunque con mayor frecuencia que en los adultos, sobreviene el síndrome neurotrópico, con consecuencias fatales ${ }^{38-40}$ 
Tabla 3. Vacunas específicas del niño viajero: cuándo administrarlas, edad mínima, primovacunación y recuerdos

\begin{tabular}{|c|c|c|c|c|}
\hline Vacuna & $\begin{array}{c}\text { Cuándo } \\
\text { administrar (antes } \\
\text { del viaje) }\end{array}$ & Edad & Primovacunación & Recuerdo \\
\hline Cólera & $\begin{array}{l}\text { Última dosis } 7 \text { días } \\
\text { antes del viaje }\end{array}$ & $\geq 2$ años & $\begin{array}{l}>2-6 \text { años: } 3 \text { dosis } \\
>6: 2 \text { dosis }\end{array}$ & $\begin{array}{l}>2-6 \text { años: a los } \\
6 \text { meses } \\
>6 \text { : entre } 6 \text { meses y } 2 \\
\text { años si área de riesgo }\end{array}$ \\
\hline Hepatitis A & $\begin{array}{l}\text { Un mes antes, } \\
\text { pero en cualquier } \\
\text { momento }\end{array}$ & $\geq 1$ año & $0-(6-12)$ meses & $\begin{array}{l}\text { En el momento } \\
\text { actual, no } \\
\text { establecidos }\end{array}$ \\
\hline IG antihepatitis A & - & $<1$ año & $\begin{array}{l}\text { 0,02 } \mathrm{ml} / \mathrm{kg} \mathrm{IM} \\
\text { (en el glúteo) }\end{array}$ & $\begin{array}{l}\text { Protege durante } \\
6 \text { semanas }\end{array}$ \\
\hline $\begin{array}{l}\text { Encefalitis } \\
\text { centroeuropea }\end{array}$ & $\begin{array}{l}\text { Completar dos } \\
\text { dosis } 15 \text { días antes } \\
\text { del viaje }\end{array}$ & $\geq 1$ año & $\begin{array}{l}\text { 0, 1-3 meses } \\
\text { después de la } \\
\text { primera y } 9 \text {-12 } \\
\text { meses después } \\
\text { de la segunda. }\end{array}$ & $\begin{array}{l}\text { Cada 3-5 años si área } \\
\text { de riesgo }\end{array}$ \\
\hline $\begin{array}{l}\text { Encefalitis japonesa } \\
\left(\text { Ixiaro }{ }^{\circledR}\right)\end{array}$ & $\begin{array}{l}\text { Completar dos } \\
\text { dosis al menos } 15 \\
\text { días antes del viaje }\end{array}$ & $\geq 2$ meses & 0-1 mes & $\begin{array}{l}\text { Al año (pendiente } \\
\text { de establecer dosis } \\
\text { posteriores) }\end{array}$ \\
\hline $\begin{array}{l}\text { Fiebre tifoidea Ty21a } \\
\text { (oral) }\end{array}$ & 15 días antes & Cuando puedan tragar & $\begin{array}{l}3 \text { dosis (una cápsula } \\
\text { a días alternos) }\end{array}$ & $\begin{array}{l}\text { Cada 3-4 años si área } \\
\text { de riesgo }\end{array}$ \\
\hline $\begin{array}{l}\text { Fiebre tifoidea Vi } \\
\text { de polisacáridos }\end{array}$ & 15 días antes & $\geq 2$ años & Una dosis & $\begin{array}{l}\text { Cada } 3 \text { años si área } \\
\text { de riesgo }\end{array}$ \\
\hline Fiebre amarilla & $\begin{array}{l}10 \text { dias antes } \\
\text { (conviene } \\
\text { antes por si } \\
\text { aparecen efectos } \\
\text { secundarios) }\end{array}$ & $\begin{array}{l}\geq 9 \text { meses } \\
6-9 \text { meses: valorar } \\
\leq 4 \text { meses: } \\
\text { contraindicada }\end{array}$ & Una dosis & Cada 10 años \\
\hline $\begin{array}{l}\text { Meningitis } \\
\text { meningocócica } \\
\text { conjugada (Menveo }{ }^{\circledR} \\
\text { comercializada en } \\
\text { España desde julio } \\
\text { de 2010) }\end{array}$ & 15 días antes & $\begin{array}{l}2 \text { años (autorizada desde } \\
\text { los dos años desde el } 12 \\
\text { de abril del 2012; datos } \\
\text { limitados a partir de los } \\
55 \text { años) }\end{array}$ & Una dosis & $\begin{array}{l}\text { Cada 3-5 años si área } \\
\text { de riesgo (pendiente } \\
\text { modificar ficha } \\
\text { técnica) }\end{array}$ \\
\hline $\begin{array}{l}\text { Meningitis } \\
\text { meningocócica } \\
\text { conjugada } \\
\text { (Nimenrix }{ }^{\circledR} \\
\text { comercializada } \\
\text { en España desde } \\
\text { febrero de 2013) }\end{array}$ & 15 días antes & $\begin{array}{l}1 \text { año (datos limitados } \\
\text { a partir de los } 55 \text { años) }\end{array}$ & Una dosis & $\begin{array}{l}\text { No se ha establecido } \\
\text { todavía la necesidad } \\
\text { de una dosis de } \\
\text { recuerdo en niños } \\
\text { primovacunados }\end{array}$ \\
\hline $\begin{array}{l}\text { Meningitis } \\
\text { meningocócica } \\
\text { polisacáridos }\end{array}$ & 15 días antes & $\geq 2$ años & Una dosis & $\begin{array}{l}\text { Cada } 3 \text { años si área } \\
\text { de riesgo }\end{array}$ \\
\hline Rabia & $\begin{array}{l}\text { Comenzar serie } \\
\text { primaria, al menos, } \\
\text { un mes antes }\end{array}$ & $\begin{array}{l}\text { Cualquier edad (debido } \\
\text { a la gravedad de la } \\
\text { enfermedad) }\end{array}$ & 0-7-(21-28) días & En función del riesgo \\
\hline
\end{tabular}

IG: inmunoglobulina; IM: vía intramuscular. 
- Similar a los adultos: la eficacia de una sola dosis es del 98-99\% (porcentaje que se ve reducido en niños con VIH, con otras inmunodepresiones o con malnutrición) y los anticuerpos persisten entre 16 y 19 años, o incluso más tiempo ${ }^{41,42}$.

- Contraindicación específica: la vacuna está contraindicada para niños con edades por debajo de los cuatro meses de vida ${ }^{41}$ (Tabla 4), con hipersensibilidad al huevo ${ }^{42}$ y en casos de inmunosupresión ${ }^{43}$.

- Compatibilidad: se puede aplicar el mismo día que la vacuna de bacilo de Calmette-Guerin (BCG), difteria, gripe, triple vírica, antitiroidea (oral e inyectable), hepatitis A y B, poliovirus, meningitis tetravalente de polisacáridos, tétanos y tos ferina ${ }^{44,45}$. No existen datos que demuestren que exista interacción con la vacuna del virus del papiloma humano, encefalitis japonesa o varicela ${ }^{44}$. No se debe aplicar, en el momento actual, a la vez que la de la meningitis tetravalente conjugada (Menveo $\left.{ }^{\circledR}\right)^{46,47}$.

- Vacuna triple vírica y fiebre amarilla: se debe comprobar que el niño no haya recibido la vacuna triple vírica en los últimos 28 días. Si esto ha ocurrido, se informará a los padres o tutores de la posibilidad de la efectividad incompleta de la vacuna de fiebre amarilla y si el niño vuelve a área endémica, aunque hayan pasado menos de diez años, se puede considerar la revacunación.

- Vacuna contra la varicela y vacuna de la fiebre amarilla: no existen datos que demuestren interacción entre las dos vacunas ${ }^{44}$.

- Valoración riesgo/beneficio: cuanto menor es el riesgo de adquirir la enfermedad, mayor es la ratio del riesgo/beneficio de la vacuna. Por lo tanto, si un lactante viaja a un país donde la incidencia de fiebre amarilla es baja, no existe un brote en el momento del viaje y la estancia es corta, se debe valorar los riesgos/beneficios de la vacunación cuidadosamente.

\section{Novedades}

Está contraindicada la vacunación a la madre si está con lactancia materna ${ }^{48,49}$.

Los Centros para el Control y Prevención de las Enfermedades (CDC) de EE. UU. contraindican la vacunación en caso de inmunodeficiencia primaria, neoplasia maligna, trasplante, inmunomoduladores (bloqueante de la interleukina I, anticuerpos monoclonales dirigidos a células del sistema inmunitario ${ }^{41}$; no contraindican la vacunación en caso de que tras una cirugía se haya extirpado el timo de manera accidental o se haya irradiado esta glándula de forma indirecta en un pasado lejano ${ }^{41}$. La Organización Mundial de la Salud (OMS) especifica un nuevo término "áreas/países de riesgo con transmisión de fiebre amarilla"11. El término "área" indica una determinada región del país donde existe riesgo de la enfermedad. Además, modifica las áreas de riesgo de fiebre amarilla y las subdivide en endémica, riesgo transicional, bajo riesgo y no riesgo (ver las direcciones URL mencionadas antes). Por ejemplo, Tanzania ha pasado de ser un país endémico de fiebre amarilla a un país de "no riesgo" en la mayor parte de su extensión.

\section{Meningitis meningocócica}

La meningitis meningocócica es una enfermedad bacteriana transmitida por vía respiratoria con una alta tasa de letalidad y mortalidad en lactantes, niños $y$ adolescentes.

Tabla 4. Indicaciones de la vacuna frente a fiebre amarilla según edad

\begin{tabular}{|l|l|}
\hline \multicolumn{1}{|c|}{ Edad } & \multicolumn{1}{c|}{ Indicación de vacuna de fiebre amarilla } \\
\hline$\geq 9$ meses & Vacunar, si no existe contraindicación \\
\hline $6-9$ meses & $\begin{array}{l}\text { Valorar riesgo/beneficio, por mayor susceptibilidad a presentar encefalitis postvacunal. } \\
\text { Para tomar la decisión de vacunar se debe comparar el peligro de exposición con los } \\
\text { peligros teóricos de la encefalitis posvacunal }\end{array}$ \\
\hline$\leq 4$ meses & Contraindicada por riesgo alto de encefalitis posvacunal \\
\hline
\end{tabular}




\section{Importancia de la enfermedad en el niño que viaja}

Los lactantes tienen mayor riesgo de padecer la enfermedad; posteriormente, las tasas de enfermedad disminuyen, pero vuelven a aumentar en la adolescencia y en los principios de la edad adulta ${ }^{49-51}$.

\section{Indicaciones de vacunación en el niño que viaja}

Se vacunará al niño de la meningitis si la estancia va a ser en el cinturón subsahariano (áreas con epidemias frecuentes de meningitis meningocócica en África durante 2010: http://wwwnc.cdc.gov/ travel/yellowbook/2012/chapter-3-infectious-di seases-related-to-travel/meningococcal-disease. htm\#2572), fundamentalmente durante la estación seca, y/o en La Meca (peregrinación durante Hajj y Umrah ${ }^{52}$ y/o en un área/país con brote en el momento del viaje (entre el 1 de enero y el 17 de abril del 2012, se comunicaron brotes de meningitis en 10 de los 14 países del cinturón africano) ${ }^{53}$. No está claramente establecida la duración del viaje a partir de la cual es necesaria la vacunación. Algunos autores la recomiendan a partir del mes de estancia, pero siempre considerando, al menos, la historia clínica del niño y el tipo de viaje y de viajero (VRF, etc.) $)^{39,51}$.

\section{Consideraciones de edad respecto a la vacuna tetravalente}

Debe utilizarse la vacuna cuadrivalente conjugada contra meningococos de los serogrupos A, C, $W_{135}$ eY, a partir de los dos años para Menveo ${ }^{\oplus}$ (esta indicación es a partir del 12 de abril de 2012) ${ }^{46}$. No existe presentación pediátrica. La vacuna de polisacáridos no se recomienda en niños menores de dos años debido a su baja inmunogenicidad y a la corta duración de protección en este grupo de edad ${ }^{54}$.

La vacuna conjugada, en relación con la vacuna de polisacáridos, probablemente tiene mayor duración, menor número de hiporrespondedores con las dosis de recuerdo y mayor efecto sobre la eliminación de portadores ${ }^{50-55}$

La Tabla 3 describe las vacunas contra la meningitis tetravalente ${ }^{5,46,55}$. En España, ninguna vacuna tetravalente de meningitis meningocócica, hasta el momento actual, está autorizada en menores de un año.

\section{Novedades}

La vacuna cuadrivalente conjugada Nimenrix ${ }^{\circledR}$, contra meningococos de los serogrupos A, C, $W_{135}$ e Y, está disponible en los Centros de Vacunación Internacional desde febrero de 2013 , se recomienda a partir del año de vida ${ }^{55}$ (Tabla 3).

Indicaciones de vacunación en el niño que viaja: en EE. UU se recomienda Menveo ${ }^{\circledR}$ entre los 9 meses de vida y los 55 años, con revacunaciones cada 3-5 años, en función de la edad a la que se haya administrado la primera dosis y la continuidad del riesgo ${ }^{50}$.

\section{Encefalitis japonesa}

Es una enfermedad vírica del sistema nervioso central trasmitida por la picadura de mosquitos de la especie Culex. La mayoría de los casos son asintomáticos; sin embargo, ocasionalmente puede producir una encefalitis con secuelas permanentes y letalidad elevada ${ }^{56}$.

\section{Importancia de la enfermedad en el niño que realiza un viaje internacional}

En países endémicos es una enfermedad de la infancia; sin embargo, en viajeros puede darse a cualquier edad. La susceptibilidad a la afección clínica es mayor en la infancia ${ }^{39}$.

\section{Indicaciones de vacunación}

Estancias en áreas endémicas (áreas en riesgo de encefalitis japonesa: http://wwwnc.cdc.gov/travel/yellowbook/2012/chapter-3-infectious-diseases-related-to-travel/japanese-encephalitis.htm\#2473). Se debe considerar también si el viaje es superior a un mes y si la permanencia es en áreas rurales y durante la estación de transmisión (varía según cada país) ${ }^{56}$.

\section{Consideraciones de edad: vacuna de encefalitis japonesa}

Actualmente, la única vacuna disponible en España es Ixiaro ${ }^{\circledR}$ (virus entero inactivado, absorbida) 
autorizada desde el año 2009 solamente para viajeros de edad igual o superior a 18 años ${ }^{57}$ (Tabla 3). Sin embargo, y tras múltiples ensayos clínicos, el Comité de Medicamentos de Uso Humano de la Agencia Europea de Medicamentos, en un reciente dictamen (13/12/2012), recomendó la ampliación de la indicación desde los dos meses de edad en adelante $e^{58-61}$.

\section{Vacunación en otros países}

En Asia, especialmente en China, está comercializada una vacuna de virus vivos atenuados SA1414-2 autorizada a partir de los nueve meses de edad $^{62}$. La vacuna es de una sola dosis, produce fiebre transitoria en el $5-10 \%$ de los vacunados y reacciones locales en el 1-3\%. No existen casos, hasta el momento actual, reportados de encefalitis postvacunal. En Australia y en Tailandia se ensaya una vacuna combinada de virus vivos, con fiebre amarilla (www.who.int/ith/vaccines/japanese encephalitis/en/index.html). Por lo tanto, y siempre en función del riesgo, se puede valorar la vacunación en el lugar de destino.

\section{Novedades}

Indicaciones de vacunación de Ixiaro ${ }^{\circledR}$ : desde el año 2013, a partir de los dos meses de vida ${ }^{61}$.

Indicaciones de revacunación de Ixiaro ${ }^{\circledR}$ : en Europa y en EE. UU. se recomienda administrar recuerdo de Ixiaro ${ }^{\circledR}$ si la última dosis se administró hace más de un año y permanece en una área de riesgo $^{57,59}$. La autorización de revacunaciones posteriores aún no ha sido establecida.

\section{Encefalitis centroeuropea}

Es una enfermedad vírica del sistema nervioso central trasmitida por la picadura de una garrapata a personas que se encuentran en bosques, campos o pastos, o por consumo de leche no pasteurizada contaminada. La mayoría de los casos son asintomáticos, pero ocasionalmente puede producir una encefalitis con secuelas permanentes. La tasa de mortalidad por casos es de aproximada- mente un 1\%. La mayor incidencia de la enfermedad se da al oeste de Siberia. La mayoría de los casos se producen entre mayo y noviembre. La susceptibilidad a la afección clínica no es mayor en la infancia ${ }^{63,64}$.

\section{Indicaciones de vacunación en el niño que realiza un viaje internacional}

Estancia en el área endémica (áreas endémicas de encefalitis centroeuropea: www.tbefacts.com/ about-tick-borne-encephalitis.html), durante la estación de transmisión. No está claramente establecida la duración del viaje a partir de la cual es necesaria la vacunación. Algunos autores recomiendan la vacunación incluso por periodos inferiores a una semana ${ }^{65}$. Se debe considerar siempre la historia clínica del niño, su estancia en áreas rurales y el tipo de alojamiento (campistas...) ${ }^{66}$.

\section{Consideraciones de edad: vacuna de encefalitis centroeuropea}

Vacuna de virus entero inactivado. En menores de 12-15 años, según vacuna autorizada, debe utilizarse la presentación pediátrica (Tablas 3 y 5 ) ${ }^{63}$. Contraindicación específica: hipersensibilidad al huevo.

\section{Hepatitis A}

La hepatitis A es una infección vírica de transmisión fecal-oral que produce un cuadro agudo de afectación hepática, pudiendo llegar a una hepatitis fulminante en un $2 \%$ de las personas mayores de 40 años ${ }^{67}$.

\section{Importancia de la enfermedad en niños}

En menores de cinco años, en la mayoría de las ocasiones es una enfermedad asintomática, anictérica ${ }^{68}$. El principal problema es que los niños pueden excretar el virus durante un largo periodo de tiempo y contagiar a individuos no inmunes, en los que la enfermedad puede tener importantes consecuencias. La enfermedad es endémica en países de baja renta ${ }^{67,68}$. 


\begin{tabular}{|c|c|c|}
\hline Presentaciones pediátricas & Edad & Pauta de administración \\
\hline Fsme-Immun ${ }^{\circledR}$ & 1-15 años & $\begin{array}{l}\text { 0, 1-3 meses después de la primera y 5-12 meses } \\
\text { después de la segunda. Si viaja o persiste en área } \\
\text { de riesgo, recuerdo entre 3-5 años }\end{array}$ \\
\hline Encepur ${ }^{\circledast}$ & 1-11 años & $\begin{array}{l}\text { 0, 1-3 meses después de la primera y 9-12 meses } \\
\text { después de la segunda. Si viaja o persiste en área } \\
\text { de riesgo, recuerdo entre 3-5 años }\end{array}$ \\
\hline Ticovac $^{\circledR}$ & 1-15 años & $\begin{array}{l}\text { 0, 1-3 meses después de la primera y 5-12 meses } \\
\text { después de la segunda. Si viaja o persiste en área } \\
\text { de riesgo, recuerdo entre 3-5 años }\end{array}$ \\
\hline
\end{tabular}

\section{Indicaciones de vacunación en el niño que realiza un viaje internacional}

Estancia en países de endemicidad media o alta, especialmente si permanecen en lugares con condiciones higiénico-sanitarias deficientes (áreas endémicas de hepatitis A: http://wwwnc.cdc.gov/ travel/yellowbook/2012/chapter-3-infectious-di seases-related-to-travel/hepatitis-a.htm\#2394) ${ }^{69}$. La indicación, independientemente del tiempo de estancia, se debe realizar en niños que acuden a guarderías, con VIH, inmunodeficiencias, hepatopatía o con trastornos de la coagulación ${ }^{67}$.

La inmunoglobulina (IG) preexposición está recomendada en niños menores de 12 meses o si los padres no son partidarios de la vacunación (Tabla 6); también se puede administrar postexposición $^{67,70,71}$.

\section{Consideraciones de edad: vacuna de hepatitis $A$}

Es la segunda enfermedad prevenible más frecuente en los viajes internacionales. La vacuna es de virus enteros inactivados y existen presentaciones pediátricas (Tabla 7).

Efectividad vacunal: con la primera dosis, la protección aparece a las 2-4 semanas y dura al menos un año, mientras que tras la segunda dosis se asume que la protección es permanente (Tabla 3). No existe, en la actualidad, recomendación de revacunación ${ }^{67}$.

Contraindicación específica de $\operatorname{Havrix}^{\circledR}$ y Vaqta $^{\circledR}$ : alergia a la neomicina ${ }^{72,73}$. Contraindicación específica de Epaxal ${ }^{\circledR}$ : alergia al huevo ${ }^{74}$.

Vacuna combinada antihepatitis A+B: no se puede administrar en profilaxis postexposición, la pauta vacunal es de tres dosis (0-1-6 meses) y se utiliza poco en niños españoles por la alta cobertura de la vacunación antihepatitis $B^{34}$.

Puntos clave: la vacuna de hepatitis A está contraindicada antes del año de edad, por producir interferencia con anticuerpos maternos; se recomienda administrar la primera dosis de vacuna de hepatitis $\mathrm{A}$ al menos un mes antes del viaje internacional, pero en los niños protege incluso administrándola el día antes de la partida (excepto en niños inmunodeprimidos).

\section{Novedades}

Los CDC recomiendan vacunar, durante los primeros 60 días tras su llegada, a las personas que van a convivir con niños adoptados originarios de paí-

\section{Tabla 6. Prevención de la hepatitis A según la edad}

\begin{tabular}{|l|l|}
\multicolumn{1}{|c|}{ Edad } & \multicolumn{1}{c|}{ Prevención de hepatitis A } \\
\hline$<1$ año & $\bullet$ Una dosis de IG intramuscular $(0,02 \mathrm{ml} / \mathrm{kg})$ \\
\hline$\geq 1$ año & $\begin{array}{l}\bullet \text { Dos dosis de vacuna, separadas entre sí, al menos, } 6 \text { meses } \\
\text { • En niños inmunodeprimidos se puede valorar IG y primera dosis de vacuna }\end{array}$ \\
\hline
\end{tabular}

IG: inmunoglobulina. IM: vía intramuscular. 


\begin{tabular}{|l|l|l|}
\hline \multicolumn{1}{|c|}{ Tabla 7. Vacuna de hepatitis A: presentaciones pediátricas comercializadas y edad de administración } \\
\hline \multicolumn{1}{|c|}{ Havrix $^{\circledR}$} & \multicolumn{1}{|c|}{ Vaqta $^{\circledR}$} & \multicolumn{1}{c|}{ Epaxal $^{\circledR}$} \\
\hline De 1-18 años 720 UE* $^{*}$ & De 2-17 años 25 UE* $^{*}$ & A partir de 1 año de vida \\
\hline$\geq 19$ años 1440 UE* $^{*}$ & $\geq 18$ años 50 UE* $^{*}$ & \\
\hline
\end{tabular}

*Cada preparado emplea unidades distintas para medir la cantidad de antígeno.

ses con endemicidad media o alta (ver la dirección web mencionada antes ${ }^{75}$.

\section{Fiebre tifoidea}

Es una enfermedad bacteriana sistémica de transmisión fecal-oral cuya tasa de letalidad después de la era antibiótica es de un $1 \%$.

\section{Importancia de la enfermedad en el niño}

En zonas endémicas es más común en los preescolares y escolares entre 5 y 19 años ${ }^{76,77}$.

\section{Indicaciones de vacunación en el niño que realiza un viaje internacional}

Estancias en países de baja renta, fundamentalmente en el subcontinente indio, pero también existe alta incidencia en México. La duración del viaje a partir de la cual es necesaria la vacunación no está claramente establecida; sí se debe recomendar a los viajeros que permanezcan durante un largo periodo de tiempo en un área de riesgo $^{76-78}$. Se debe considerar la historia clínica del niño (antecedentes de problemas gastrointestinales, enfermedad crónica...), el tipo de viaje (fundamentalmente indicada en VRF), si es un viaje a áreas rurales o ciudades pequeñas, y si hay baja posibilidad de garantizar una adecuada asistencia médica.

\section{Consideraciones de edad: vacuna de fiebre tifoidea}

Vacuna de parenteral de polisacárídos (Vi) y de microorganismos vivos atenuados (Ty21a). La edad es un factor determinante para la elección del tipo de vacuna, fundamentalmente porque la vacuna de microorganismos vivos es oral (Tablas 3 y 8$)^{79,80}$. Compatibilidad de la vacuna oral: es similar a los adultos. La OMS establece que se debe esperar, tras la toma de la última dosis, al menos tres días para iniciar quimioprofilaxis con mefloquina o progruanil $^{81}$. Si el niño está con un tratamiento antibiótico se debe esperar tres días para iniciar la vacunación; sin embargo, los CDC establecen un periodo superior a tres días tras finalizar este tratamiento $^{76,82}$.

La vacuna oral no interfiere con las vacunas inyectables de microorganismos vivos ${ }^{83}$.

Las vacunas disponibles de fiebre tifoidea tienen una efectividad variable entre un 51 y un 77\%; por lo tanto, siempre hay que llevar a cabo medidas de control higiénico.

\section{Rabia}

La rabia es una enfermedad vírica del sistema nervioso central, transmitida por mordedura o lamido de un animal infectado, mortal sin tratamiento y prevenible mediante vacunación ${ }^{84}$. La infección se produce en áreas en las que exista un brote en el

Tabla 8. Indicaciones de la vacuna de fiebre tifoidea según la edad

\begin{tabular}{|l|l|}
\hline \multicolumn{1}{|c|}{ Edad } & \multicolumn{1}{c|}{ Prevención de la fiebre tifoidea } \\
\hline$<2$ años & Precauciones con agua y alimentos \\
\hline $2-5$ años & $\begin{array}{l}\text { Precauciones con agua y alimentos + vacuna de polisacáridos (inyectable); refuerzo } \\
\text { cada } 2-3 \text { años, si el niño persiste en área de riesgo }\end{array}$ \\
\hline$>5$ años & $\begin{array}{l}\text { Precauciones con agua y alimentos más vacuna de polisacáridos o vacuna oral (si } \\
\text { pueden tragar las capsulas); refuerzo cada } 3 \text { años, si el niño persiste en área de riesgo }\end{array}$ \\
\hline
\end{tabular}


momento del viaje y en muchos países con baja renta ${ }^{84}$. Los casos de rabia en turistas ocurren con frecuencia en Filipinas ${ }^{85}$ (áreas en riesgo de rabia: http://gamapserver.who.int/mapLibrary/Files/ Maps/Global_Rabies_ITHRiskMap.png).

\section{Importancia de la enfermedad en niños}

Los niños son un grupo de riesgo para las mordeduras de animales. El mayor peligro radica en que no les cuenten a sus padres el antecedente de mordedura o lamido de algún animal durante el viaje.

\section{Indicación de vacunación en el niño que realiza un viaje internacional}

Las indicaciones varían según las guías consultadas, pero la mayoría coinciden en realizar una quimioprofilaxis preexposición si en el área de destino el acceso sanitario está a más de 24 horas; $\sin$ embargo, la duración del viaje a partir de la cual es necesaria la vacunación no está claramente establecida ${ }^{84,86}$. A favor de la vacunación preexposición, están la posibilidad de una exposición no reconocida, sobre todo en niños, la no administración de IG, la afectación "psicológica" en caso de mordedura, la facilidad del régimen postexposición (0-3 días frente a 0-3-7-14-28 días)... En contra de la vacunación preexposición está el precio de la vacuna y la baja probabilidad de exposición.

La duración del viaje a partir de la cual es necesaria la vacuna en niños no está claramente establecida. De forma general, la vacunación se debe considerar en función de la historia clínica, el tipo de viaje (fundamentalmente indicada en VRF), si es un viaje a áreas rurales, selváticas y/o ciudades pequeñas, si se van a realizar visitas a cuevas y la accesibilidad de los servicios sanitarios de la zona.

\section{Consideraciones de edad: vacuna de rabia}

Es una vacuna de virus enteros inactivados ${ }^{87}$. No existen presentaciones pediátricas. La vacuna de rabia no tiene límite de edad y no hay variación de dosis. La gravedad de la enfermedad prevalece sobre todas las contraindicaciones de la vacuna. La pauta vacunal pre- y postexposición es similar al adulto.

\section{Consulta previaje}

Se debe informar a la familia de la posibilidad de vacunación postexposión y de la posibilidad de que en el país de destino no exista o sea muy difícil encontrar la IG y/o la vacuna.

\section{Profilaxis preexposición}

Se administra con una pauta de 0-7-(21-28) días. En la mayor parte de los casos, no están indicadas dosis de refuerzo ${ }^{84}$ (Tabla 3).

\section{Profilaxis postexposición en niños vacunados}

Lavado vigoroso de la herida más dos dosis de vacunación a los 0-3 días. No está indicada la IG ${ }^{84}$.

\section{Novedades}

Profilaxis postexposición en niños no vacunados: lavado vigoroso de la herida más IG más cuatro dosis de vacuna 0-3-7-14 días ${ }^{84}$, frente a lavado vigoroso de la herida más IG más cinco dosis de vacuna 0-3-7-14-(21-28) días ${ }^{87}$. La IG se debe ajustar por kilo de peso y se administrará como máximo siete días después de la primera dosis de vacuna ${ }^{84,86}$.

\section{Cólera}

Es una enfermedad bacteriana transmitida por ingestión de agua o alimentos contaminados. La letalidad en niños es alta ${ }^{88}$. El cólera es endémico, y en determinadas ocasiones se convierte en epidémico, en ciertas regiones de Asia, África, Centroamérica y Sudamérica ${ }^{88}$ (áreas con brotes de cólera durante los años 2009-2010: www.who.int/chole ra/countries/en/index.html).

\section{Indicaciones de vacunación en el niño que realiza un viaje internacional}

Es excepcional. La vacuna confiere una inmunidad incompleta frente al cólera (aproximadamente el $85 \%$ durante los primeros cinco meses y luego des- 
ciende) y frente a la diarrea del viajero (indicación no recogida en la ficha técnica) $)^{89,90,91}$.

\section{Consideraciones de edad: vacuna de cólera}

Ningún país debe exigir como requerimiento de entrada la vacuna de cólera ${ }^{36}$.

Vacuna de bacteria inactivada, Dukoral ${ }^{\oplus 1}$, con posología distinta en función de la edad (Tablas 3 y 9). La efectividad en niños no es muy alta y no se debe administrar hasta los dos años de edad.

Compatibilidad: se debe administrar en diferente fecha que la vacuna de tifus oral y puede interaccionar con mefloquina o cloroquina.

Contraindicación específica: fenilcetonuria (contiene aspartato $)^{91}$.

\section{Tuberculosis}

\section{Importancia de la enfermedad en niños}

El diagnóstico de infección latente por tuberculosis o infección tuberculosa en niños, por lo general, constituye un "fenómeno centinela" que suele representar la transmisión reciente de $M$. tuberculosis. Además, los niños y adolescentes están expuestos a un mayor peligro de evolución de la infección a la enfermedad, con consecuencias fatales sin tratamiento ${ }^{92}$.

La mayor prevalencia de la infección y enfermedad se encuentra en países de África, Asia, Centroamérica y Sudamérica (tasas de incidencia estimadas de tuberculosis en el año 2009: http://wwwnc.cdc. gov/travel/yellowbook/ 2012/chapter-3-infectious-diseases-related-to-travel/tuberculosis. htm\#2805).

\section{Consideraciones de edad: vacuna de bacilo de Calmette-Guerin}

La vacuna de BCG, compuesta de bacilo atenuado, proporciona una protección global del 50\% frente a la enfermedad tuberculosa en la infancia; previene especialmente de la meningitis tuberculo$\mathrm{sa}^{39,93}$. Los datos respecto a la efectividad e indicaciones vacunales son aún controvertidos.

\section{Indicaciones de vacunación en el niño que realiza un viaje internacional}

Se puede valorar la vacunación en lactantes y niños, con prueba de tuberculina negativa, que se desplacen durante largos periodos de tiempo a países con alta endemicidad (ver dirección web mencionada antes). Un factor que puede ayudar en la toma de decisión es la inclusión de la vacuna en el calendario del país de destino ${ }^{94}$. En niños mayores, si no están vacunados, y siempre en viajes de larga estancia a países con endemicidad alta, se puede realizar la prueba de tuberculina antes y, en su caso, después del viaje ${ }^{39}$.

\section{Polio}

Es una enfermedad vírica aguda transmitida por vía fecal-oral, por lo general de curso banal en niños. La poliomielitis también se conoce como "parálisis infantil” porque afecta con más frecuencia a niños, pero la frecuencia de parálisis en esta población es menor que la observada en adultos ${ }^{95}$.

\section{Importancia de la enfermedad en niños}

Desde el punto de vista de la erradicación de la enfermedad, los niños viajeros son potentes factores de transmisión y de una posible reintroducción del virus en áreas libres de polio ${ }^{96}$.

Tabla 9. Prevención del cólera según la edad

\begin{tabular}{|l|l|}
\hline \multicolumn{1}{|c|}{ Edad } & \multicolumn{1}{c|}{ Prevención del cólera } \\
\hline$<2$ años & Precauciones con agua y alimentos \\
\hline 2-6 años & $\begin{array}{l}\text { Precauciones con agua y alimentos más tres dosis de vacuna separadas una semana; } \\
\text { refuerzo cada } 6 \text { meses, si el niño persiste en área de riesgo }\end{array}$ \\
\hline$>6$ años & $\begin{array}{l}\text { Precauciones con agua y alimentos más dos dosis de vacuna separadas una semana; } \\
\text { refuerzo cada } 2 \text { años, si el niño persiste en área de riesgo }\end{array}$ \\
\hline
\end{tabular}




\section{Indicaciones de vacunación en el niño que realiza un viaje internacional}

Niños mayores de seis semanas de vida con estancias en países donde circule el virus salvaje, que en el momento actual son Pakistán, Afganistán y Nigeria ${ }^{97}$. Los niños que viajen a una zona endémica deberían haber recibido por lo menos cuatro dosis. La cobertura de vacunación en España es muy alta ${ }^{34}$.

\section{Consideraciones de edad: vacuna de polio}

Debe utilizarse la vacuna parenteral inactivada ${ }^{34}$.

\section{Novedades}

La India, en el momento actual, ya no se considera país endémico de polio ${ }^{97}$.

\section{Sarampión}

El sarampión es una enfermedad vírica exantemática de la infancia transmitida por vía respiratoria. Las complicaciones, una o más, se producen aproximadamente en un 30\% de los $\operatorname{casos}^{98}$. La distribución de la enfermedad es global; en los países industrializados ocasionalmente aparecen brotes, fundamentalmente debidos a personas que rechazan la vacunación ${ }^{98}$. Los niños han de haber recibido al menos dos dosis de vacuna triple vírica (sarampión, rubéola y parotiditis), y los adolescentes y adultos que no conozcan su estado inmunitario deben recibir al menos una dosis ${ }^{99}$.

\section{Indicaciones de vacunación en el niño que realiza un viaje internacional}

En función del tiempo de estancia, y particularmente para niños VRF, se recomienda vacunar con vacuna triple vírica (sarampión, rubéola y parotiditis) a partir de los seis meses. Las revacunaciones se realizarán, según calendario vacunal, a los 12-15 meses y 2-4 años (por lo tanto, si se administra una dosis antes del año de edad, el niño se considera como no vacunado) ${ }^{34}$. La recomendación de enero de 2013, de la Asociación Española de Pediatría, es administrar la primera dosis de triple vírica a los 12 meses y la segunda dosis a los dos años de vida ${ }^{34}$.

\section{Gripe}

Es una enfermedad vírica aguda transmitida por vía respiratoria, por lo general de curso banal en niños sanos.

\section{Importancia de la enfermedad en niños}

Durante la fase inicial de las epidemias en los países industrializados, tanto la infección como las epidemias se manifiestan fundamentalmente en los niños de edad escolar. Los escolares infectan a otros miembros de la familia y a otros niños y adultos. Las tasas de ataque específicas por edad durante una epidemia reflejan la inmunidad persistente derivada de la exposición previa a cepas relacionadas con el subtipo causante de la epidemia, de modo que la incidencia de infección suele ser más alta en niños de edad escolar que nunca han estado en contacto con el virus ${ }^{100,101}$.

\section{Indicaciones de vacunación en el niño que realiza un viaje internacional}

Niños mayores de seis meses, sobre todo con enfermedad cardiopulmonar, insuficiencia renal, inmunodeprimidos y VIH positivos, que viajan a un país tropical o a áreas del mundo donde se han declarado brotes de gripe o de gripe aviar altamente patógena ${ }^{39,53}$.

\section{Otras consideraciones}

El virus de la gripe puede darse durante todo el año en países tropicales, y de abril a septiembre en el hemisferio sur. La probabilidad de poder conseguir la vacuna para el hemisferio opuesto antes de llegar es baja, se debe valorar como opción realizar la vacunación tan pronto como sea posible al llegar al lugar de destino ${ }^{100-102}$.

\section{Hepatitis B}

La hepatitis B es una enfermedad vírica de transmisión por exposición percutánea y a través de las mucosas a los líquidos corporales infectantes. En los viajeros internacionales, el mecanismo de transmisión más frecuente es por contagio se- 
xual $^{103}$. El virus de la hepatitis B puede ser la causa de hasta el $80 \%$ de los carcinomas hepatocelulares en todo el mundo ${ }^{103}$. La enfermedad es de distribución mundial. La prevalencia de portadores es del 8-20\% en los países de África, Sudeste Asiático, Extremo Oriente, Islas del Pacífico, cuenca del Amazonas y el Caribe (prevalencia de la hepatitis B crónica durante el año 2006: http://wwwnc.cdc. gov/travel/yellowbook/2012/chapter-3-infec tious-diseases-related-to-travel/hepatitis-b. htm\#2403). La prevalencia es algo menor, del 2 al $7 \%$, en el este de Europa, en Asia Central y en países de América Central y del Sur. Los países industrializados tienen una prevalencia inferior al $2 \%{ }^{103}$

\section{Importancia de la enfermedad en niños}

En los lactantes, la infección aguda por el virus suele ser asintomática. Un 10\% de los niños tiene un cuadro ictérico (a diferencia del 30-50\% de los adultos). Sin embargo, existe infección crónica en un $90 \%$ de los lactantes infectados al nacer, en un 20-50\% de los niños infectados entre uno y cinco años y en aproximadamente el 1-10\% de las personas infectadas a partir de esa edad. El riesgo de hepatitis fulminante es mayor en los recién nacidos de madre infectada ${ }^{103,68}$

\section{Indicaciones de vacunación en el niño que realiza un viaje internacional}

Está indicada para estancias en un área endémica. Los adolescentes deben ser adecuadamente informados de la prevención de la hepatitis B y de otras enfermedades de transmisión sexual. La cobertura vacunal de la hepatitis B de los niños nacidos en
España a partir del 1980 es muy alta. Existen presentaciones pediátricas de la vacuna que se deben utilizar hasta los 15 años de vida ${ }^{34}$.

\section{QUIMIOPROFILAXIS ANTIPALÚDICA}

La malaria es una de las enfermedades más graves que puede adquirir el niño durante el viaje. Los niños que padecen la enfermedad tienen más riesgo de alcanzar altos niveles de parasitemia en poco tiempo, de complicaciones graves, incluyendo shock, convulsiones, coma y muerte. Los signos iniciales de la enfermedad, como la fiebre, se pueden confundir con otras causas de fiebre, retrasando el diagnóstico y por lo tanto el tratamiento de la enfermedad ${ }^{104}$

Ninguno de los antimaláricos proporciona una protección completa. Por lo tanto, la prevención está basada en la combinación de la quimioprofilaxis con información sobre prevención de picaduras $^{105-108}$.

Las Tablas 10 a 13 describen los principios generales que debe seguir el médico especialista en Medicina del viajero acerca de las recomendaciones de antimaláricos en niños.

\section{Consideraciones en niños}

- Hay que informar a los padres de que la sobredosificación de los medicamentos antimaláricos puede ser muy grave. Nunca se debe dejar la medicación al alcance de los niños ${ }^{16}$. Dosis pediátricas: se deben ajustar las dosis por peso, utilizar presentaciones pediátricas y conocer

Tabla 10. Principales fármacos utilizados en la quimioprofilaxis de la malaria en niños

\begin{tabular}{|c|c|c|}
\hline $\begin{array}{c}\text { Áreas según sensibilidad a } \\
\text { antipalúdicos }\end{array}$ & Fármaco & Fármaco comercializado en otros países \\
\hline Área sensible a cloroquina & Cloroquina & \multirow{3}{*}{$\begin{array}{l}\text { En algunos países, para viajes a áreas donde } \\
\text { coexisten Plasmodium vivax y falciparum, se utiliza } \\
\text { como quimioprofilaxis la Primaquina a partir del } \\
\text { año de vida (previamente se confirma que no existe } \\
\text { déficit de glucosa } 6 \text { fostato deshidrogenasa). En } \\
\text { España, aún no está comercializada }\end{array}$} \\
\hline Área resistente a cloroquina & $\begin{array}{l}\text { Atovacuona-proguanil } \\
\text { Mefloquina } \\
\text { Doxiciclina }\end{array}$ & \\
\hline Área resistente a mefloquina & $\begin{array}{l}\text { Atovacuona-proguanil } \\
\text { Doxiciclina } \\
\text { Azitromicina }\end{array}$ & \\
\hline
\end{tabular}


Tabla 11. Principio activo, presentaciones comerciales y pautas de quimioprofilaxis antimalárica en niños Mefloquina tabletas $250 \mathrm{mg}\left(\right.$ Lariam $\left.^{\circledR}\right)$ :

Un comprimido una vez a la semana. Comenzar una semana antes de llegar a la zona de riesgo, mantener durante el tiempo de estancia y continuar hasta cuatro semanas después de abandonar el área de riesgo

Cloroquina (fosfato de cloroquina) comprimidos $250 \mathrm{mg}$ (150 mg base) (Resochin ${ }^{\circledR}$ ):

Dos comprimidos una vez a la semana. Comenzar una semana antes de llegar a la zona de riesgo, mientras se permanezca allí y continuar hasta cuatro semanas después de abandonar el área de riesgo.

\section{Doxiciclina cápsulas $100 \mathrm{mg}$ (Doxiclat ${ }^{\circledR}$ ):}

Un comprimido al día. Comenzar un día antes de llegar a la zona de riesgo, mientras se permanezca allí y continuar hasta 28 días después de abandonar el área de riesgo

Atovacuona-proguanil comprimidos pediátrico, 62,5 mg atovacuona y $25 \mathrm{mg}$ de proguanil; envase 12 (Malarone ${ }^{\circledR}$ ): Un comprimido al día. Comenzar un día antes de llegar a la zona de riesgo, mientras se permanezca allí y continuar hasta una semana después de abandonar el área de riesgo

Atovacuona-proguanil comprimidos adulto, $250 \mathrm{mg}$ atovacuona y $100 \mathrm{mg}$ de proguanil; env 12 (Malarone ${ }^{\circledR}$ ):

Se utiliza a partir de $40 \mathrm{~kg}$. Pauta igual que Malarone ${ }^{\circledR}$ pediátrico

las edades y pesos a los que se puede administrar cada antipalúdico ${ }^{109}$.

- Se debe implicar a los padres: por ejemplo, al elegir la quimioprofilaxis hay padres que prefieren administrar un medicamento diariamente que semanalmente. Hay que asegurarse de dar toda la información para asegurar el éxito.
- Administración del medicamento con bebida o comida dulce: la mayoría de los fármacos tienen un sabor amargo, por lo que deben ingerirse con comida o bebida dulce.

- Fraccionar el medicamento: si es necesario el ajuste de dosis, se puede fraccionar la tableta del Lariam $^{\circledR}$, pero hay que considerar que la concentración del principio activo puede no ser

\begin{tabular}{|l|l|l|}
\hline \multicolumn{1}{|c|}{ Tabla 12. Consideraciones de edad, peso y claves en la elección del antipalúdico en niños } \\
\hline Antipalúdico & \multicolumn{1}{|c|}{ Utilización en niños } & \multicolumn{1}{c|}{ Claves } \\
\hline Cloroquina & $\begin{array}{l}\text { Se puede utilizar si peso } \\
\text { inferior a } 5 \mathrm{~kg}\end{array}$ & $\begin{array}{l}\text { Molestias gastrointestinales, cansancio, visión borrosa, } \\
\text { exacerbación de la psoriasis } \\
\text { Recomendar en áreas sensibles a cloroquina: América } \\
\text { Central, excepto Haití, y Oriente Medio }\end{array}$ \\
\hline Mefloquina & Peso superior a $5 \mathrm{~kg}$ & $\begin{array}{l}\text { No recomendar si: historia de convulsiones, patología } \\
\text { neuropsiquiátrica*, alteraciones de la conducción } \\
\text { cardíaca, insuficiencia renal... } \\
\text { Recomendar en áreas de resistencia a cloroquina: todas } \\
\text { las áreas palúdicas, excepto las previamente descritas } \\
\text { No recomendar en áreas de resistencia a la mefloquina: } \\
\text { frontera de Tailandia con Myanmar, Laos y Camboya y } \\
\text { áreas de Vietnam }\end{array}$ \\
\hline Doxiciclina & $\begin{array}{l}\text { Hipoplasia del esmalte dental permanente } \\
\text { Recomendar en áreas sensibles a doxiciclina y en áreas } \\
\text { de resistencia a mefloquina }\end{array}$ \\
\hline Atovacuona-proguanil & $\begin{array}{l}\text { Molestias digestivas, úlceras bucales, vómitos, náuseas } \\
\text { No fraccionar comprimidos de adultos para los niños, } \\
\text { la distribución de la medicación no es homogénea } \\
\text { Efectividad muy alta en prevenir malaria por P. } \\
\text { falciparum } \\
\text { Primera elección en estancias cortas } \\
\text { Recomendar en áreas sensibles a atovacuona-proguanil } \\
\text { yen áreas de resistencia a mefloquina }\end{array}$ \\
\hline & $\begin{array}{l}\text { Peso superior a } 11 \mathrm{~kg} \\
\text { (OMS) } \\
\text { Peso superior a } 5 \mathrm{~kg} \text { (CDC }\end{array}$ \\
& \\
&
\end{tabular}

*Especialmente en adolescentes, preguntar por alteraciones nerviosas, de comportamiento...

CDC: Centros para el Control y Prevención de las Enfermedades; OMS: Organización Mundial de la Salud. 


\begin{tabular}{|c|c|c|c|}
\hline Principio activo & Dosis (oral) & Valorar al dosificar & $\begin{array}{c}\text { Máxima duración de la } \\
\text { quimioprofilaxis autorizada }\end{array}$ \\
\hline Mefloquina & $\begin{array}{l}5 \text { mg sal/kg semanal; dosificar } \\
\text { por kg hasta los } 45 \mathrm{~kg} \\
>45 \mathrm{~kg} \text { : } 1 \text { tableta }\end{array}$ & $\begin{array}{l}\text { <10 kg: } 5 \text { mg sal/kg } \\
\text { 10-20 kg: } 1 / 4 \text { tableta } \\
\text { 21-30 kg: } 1 / 2 \text { tableta } \\
\text { 31-45 kg: } 3 / 4 \text { tableta }\end{array}$ & $\begin{array}{l}6 \text { meses (en largas estancias, } \\
\text { una opción es valorar } \\
\text { quimioprofilaxis estacional...) }\end{array}$ \\
\hline Cloroquina & $\begin{array}{l}5 \text { mg base/kg semanal; máxima } \\
\text { dosis: } 300 \text { mg de la base }\end{array}$ & $\begin{array}{l}<10 \mathrm{~kg}: 5 \mathrm{mg} / \mathrm{kg} \\
\text { 10-19 kg: } 1 / 2 \text { comprimido } \\
\text { 20-29 kg: } 1 \text { comprimido } \\
\text { 30-44 kg: } 1 \frac{112}{2} \text { comprimido } \\
>45 \mathrm{~kg}: 2 \text { comprimidos }\end{array}$ & $\begin{array}{l}\text { utilizado durante años; se } \\
\text { debe considerar revisión } \\
\text { oftalmológica periódica }\end{array}$ \\
\hline Doxiciclina & $\begin{array}{l}\text { 1,5-2 mg/kg diaria; máxima dosis } \\
100 \text { mg/día }\end{array}$ & $\begin{array}{l}\text { Contraindicado en menores } \\
\text { de } 8 \text { años, aunque, } \\
\text { preferentemente esperar a } \\
\text { que termine el crecimiento. }\end{array}$ & $\begin{array}{l}6 \text { meses (en largas estancias, } \\
\text { una opción es valorar } \\
\text { quimioprofilaxis estacional) }\end{array}$ \\
\hline $\begin{array}{l}\text { Atovacuona- } \\
\text { proguanil }\end{array}$ & $\begin{array}{l}\text { Dosificar por kg, con tabletas } \\
\text { pediátricas, hasta los } 40 \text { kg; } \\
>40 \text { kg: } 1 \text { tableta adultos diaria }\end{array}$ & $\begin{array}{l}\text { 11-20 kg: } 1 \text { tableta pediátrica } \\
\text { diaria } \\
\text { 21-30 kg: } 2 \text { tabletas } \\
\text { pediátricas diarias } \\
\text { 31-40 kg: } 3 \text { tabletas } \\
\text { pediátricas diarias }\end{array}$ & $\begin{array}{l}35 \text { días (probablemente } \\
\text { se amplie este periodo; } \\
\text { pendiente de modificación } \\
\text { de ficha técnica) }\end{array}$ \\
\hline
\end{tabular}

homogénea. Por este mismo motivo no se debe fraccionar el Malarone ${ }^{\circledR}$ de adultos para niños.

- Es aconsejable realizar un dibujo en el informe: cuando se recomienda el Lariam $^{\circledR}$ fraccionado, resulta de gran utilidad realizar un círculo y colorear la dosis que debe ser administrada.

- En caso de vómito: si el niño vomita durante la primera hora tras la toma, se debe repetir la dosis. No es necesario repetir la dosis si el vómito ocurre después.

- Se valorará quimioprofilaxis en función de: la zona geográfica visitada, el tipo de viaje (VRF...), la accesibilidad de los servicios sanitarios de la zona (distancia superior a 24 horas de viaje), la especie parasitaria predominante y la frecuencia de resistencia de los antipalúdicos (por ejemplo, en algunas áreas fronterizas de Tailandia hay resistencias a la Mefloquina) ${ }^{107,110}$.

\section{Autotratamiento de la malaria en niños}

No existe en la actualidad suficiente bibliografía referente a niños para recomendar el tratamiento de la malaria por los padres o tutores en caso de comenzar con clínica sospechosa (autotratamiento) ${ }^{104}$.

\section{DURANTE O DESPUÉS DEL VIAJE INTERNACIONAL}

La supervivencia en los niños con malaria puede depender de un diagnóstico precoz y un tratamiento apropiado ${ }^{110}$. Por tanto, si a pesar de adoptar todas las medidas para prevenir la malaria, el niño tiene fiebre u otra clínica como sudoración, escalofríos, náuseas, diarrea, etc., en cualquier momento entre una semana después de llegar a la zona de riesgo y tres meses (incluso más de tres meses en casos raros), se debe descartar malaria $69,111,112$. Los signos y síntomas pueden corresponder a cualquier otra enfermedad, pero es preferible confirmarlo.

Durante o después de un viaje internacional se debe consultar con un médico si el niño presenta, entre otros, síntomas o signos, fiebre o febrícula mantenida, cuadro pseudogripal, diarrea persistente que no cede con tratamiento habitual o con fiebre, o sangre en heces, coloración amarillenta de piel, manchas en la piel, etc. ${ }^{113-115}$. 


\section{AGRADECIMIENTOS}

A mis padres y hermanas

\section{CONFLICTO DE INTERESES}

Los autores declaran no presentar conflictos de intereses en relación con la preparación y publicación de este artículo.

\section{ABREVIATURAS}

BCG: bacilo de Calmette-Guerin - CDC: Centros para el Control y Prevención de las Enfermedades • IG: inmunoglobulina $\bullet$ OMS: Organización Mundial de la Salud • VIH: virus de la inmunodeficiencia humana - VRF: visiting relatives and friends (visitar a sus amigos y familiares).

8. Barnett ED, MacPherson DW, Stauffer WM, Loutan L, Hatz CF, Matteelli A, et al. The Visiting Friends or Relatives (VFR) traveler in the 21st century: time for a new definition. J Trav Med. 2010;17:153-62.

9. Ministerio de Sanidad Política Social e Igualdad. La salud también viaja. Consejos y normas sanitarias para viajeros internacionales [en línea] [consultado el 10/12/2012]. Disponible en www.mspsi.gob.es/ profesionales/saludPublica/sanidadExterior/salud/ centrosvacu.htm

10. Ministerio de Sanidad Política Social e Igualdad. Viajes internacionales y salud, situación a 1 de enero de 2012 [en línea] [consultado el 10/12/2012]. Disponible en www.msps.es/profesionales/saludPublica/ sanidadExterior/salud/viajes/nter/home.htm

11. World Health Organization. International travel and health, 2012 [en línea] [consultado el 10/12/2012]. Disponible en www.who.int/ith/en/

12. Thomas RE. Preparing patients to travel abroad safely. Part 1: Taking a travel history and identifying special risks. Can Fam Physician. 2000;46:132-8.

13. Stauffer WM, Konop RJ, Kamat D. Traveling with infants and young children. Part III: traveler's diarrhea. J Travel Med. 2002;9:141-50.

14. Stauffer WM, Konop RJ, Kamat D. Traveling with infants and young children. Part I: Anticipatory guidance: travel preparation and preventive health advice. J Travel Med. 2001;8:254-9.

15. Goodyer LI, Croft AM, Frances SP, Hill N, Moore SJ, Onyango SP, et al. Expert review of the evidence base for arthropod bite avoidance. J Travel Med. 2010; 17:182-92.

16. Stauffer WM, Kamat D, Magill AJ. Traveling with infants and children. Part IV: insect avoidance and malaria prevention. J Travel Med. 2003;10:225-40.

17. Leggat PA, Carne J, Kedjarune U. Travel insurance and health. J Travel Med. 1999;6:243-8. 
18. Leggat PA, Speare R, Kedjarune U. Traveling with children. J Travel Med. 1998;5:142-6.

19. Hargarten SW. Injury prevention: a crucial aspect of travel medicine. J Travel Med. 1994;1:48-50.

20. Withers A, Wilson AC, Hall GL. Air travel and the risks of hypoxia in children. Paediatr Respir Rev. 2011;12: 271-6.

21. Buchanan BJ, Hoagland J, Fischer PR. Pseudoephedrine and air travel-associated ear pain in children. Arch Pediatr Adolesc. 1999;153:466-8.

22. Fisher PR. Children, earache and travel. Travel Medicine Update. 1995;5:531-2.

23. Waterhouse J, Reilly J, Atkinson G. Jet-lag. Lancet. 1997;350:1611-6

24. Moline MC, Pollak CP, Monk TH. Age-related differences in recovery from simulate jet lag. Sleep. 1992; $15: 28-40$.

25. Malerczyk C, Detora L, Gniel D. Imported human rabies cases in europe, the United States, and Japan, 1990 to 2010. J Travel Med. 2011;18:402-7.

26. Brotherton JM, Delpech VC, Gilbert GL, Hatzi S, Paraskevopoulos PD, McAnulty JM. A large outbreak of influenza $A$ and $B$ on a cruise ship causing widespread morbidity. Epidemiol Infect. 2003;130:263-71.

27. Lang L. Acute gastroenteritis outbreaks on cruise ships linked to Norwalk-like viruses. Gastroenterology. $2003 ; 124: 284-5$.

28. DuPont HL, Ericsson CD, Farthing MJ, Gorbach S, Pickering LK, Rombo L, et al. Expert review of the evidence base for self-therapy of travelers' diarrhea. J Travel Med. 2009;16:161-71.

29. Forsythe CT, Ernst ME. Do fluoroquinolones commonly cause arthropathy in children? CJEM. 2007;9:459-62.

30. Ficha técnica de Rifaximina. Bama-Geve [en línea] [consultado el 10/12/2012]. Disponible en https:// sinaem4.agemed.es/consaem/especialidad.do?met odo=verFichaWordPdf\&codigo $=62250 \&$ formato $=p$ df\&formulario $=$ FICHAS

31. Neumann K. Acute altitude sickness in children. Travel Med. 1999;6:210.

32. Craig R. Sherman CR. Motion Sickness: Review of Causes and Preventive Strategies. J Travel Med. 2002;9:251-56.

33. Ward BJ, Plourde P. Travel and Sexually Transmitted Infections. J Travel Med. 2006;13:300-17.
34. Moreno-Pérez D, Álvarez García FJ, Arístegui Fernández J, Barrio Corrales F, Cilleruelo Ortega MJ, Corretger Rauet JM, et al. Calendario de vacunaciones de la Asociación Española de Pediatría: recomendaciones 2013. An Pediatr (Barc). 2013;78(1):59.e1-27.

35. Ficha técnica de Vivotif. Crucell [en línea] [consultado el 10/12/2012]. Disponible en https://sinaem4. agemed.es/consaem/especialidad.do?metodo=verF ichaWordPdf\&codigo=56563\&formato=pdf\&form ulario=FICHAS

36. World Health Organization. International Health Regulations, 2005 [en línea] [consultado el 10/12/2012]. Disponible en www.who.int/csr/ihr/ en/index.html

37. Gershman M, Staples JE. Yellow fever. En: CDC health information for international travel 2012: the yellow book. Atlanta, GA: US Department of Health and Human Services [en línea] [consultado el 10/12/2012]. Disponible en http://wwwnc.cdc. gov/travel/yellowbook/2012/chapter-3-infectious-di seases-related-to-travel/yellow-fever.htm

38. Ficha técnica de Stamaril. Sanofi Pasteur [en línea] [consultado el 10/12/2012]. Disponible en https:// sinaem4.agemed.es/consaem/fichasTecnicas.do? metodo=buscar\&numDefinitivo $=65098$

39. Stauffer WM, Kamat D. Traveling with infants and children. Part 2: immunizations. J Travel Med. 2002; 9:82-90

40. Muñoz J, Vilella A, Domingo C, Nicolas JM, de Ory F, Corachan $\mathrm{M}$, et al. Yellow fever-associated viscerotropic disease in Barcelona, Spain. Travel Med. 2008;15:202-5.

41. Staples JE, Gershman M, Fischer M; Centers for Disease Control and Prevention. Yellow fever vaccine: recommendations of the Advisory Committee on Immunization Practices (ACIP). MMWR Recomm Rep. 2010;59:1-27.

42. Osinusi K, Akinkugbe FM, Akinwolere OA, Fabiyi A. Safety and efficacy of yellow fever vaccine in children less than one-year-old. West Afr J Med. 1990; 9:200-3.

43. Sibailly TS, Wiktor SZ, Tsai TF, Cropp BC, Ekpini ER, Adjorlolo-Johnson G, et al. Poor antibody response to yellow fever vaccination in children infected with human immunodeficiency virus type 1 . Pediatr Infect Dis J. 1997;16(12):1177-9. 
44. Fletcher MA, Fabre P, Debois H, Saliou P. Vaccines administered simultaneously: directions for new combination vaccines based on an historical review of the literature. Int J Infect Dis. 2004;8:328-38.

45. Centers for Disease Control and Prevention. General recommendations on immunization. Recommendations of the Advisory Committee on Immunization Practices. MMWR. 2011;60(2):1-64.

46. Ficha técnica de Menveo. Novartis [en línea] [consultado el 10/12/2012]. Disponible en www.aemps. gob.es/informa/informeMensual/2012/marzo/in forme-medicamentos.htm

47. Veras MA, Flannery B, de Moraes JC, da Silva Teixeira AM, Luna EJ. Vaccine Coverage Survey 2007 Group. Yellow fever vaccination coverage among children in Brazilian capitals. Vaccine. 2010;28:6478-82.

48. Centers for Disease Control and Prevention. Transmission of yellow fever vaccine virus through breast-feeding-Brazil, 2009. MMWR. 2010;59(5): 130-2.

49. Cohn A, Jackson ML. Meningococcal Disease. In CDC health information for international travel 2012: the yellow book. Atlanta, GA: US Department of Health and Human Services [en línea] [consultado el 10/12/2012]. Disponible en http://wwwnc cdc.gov/travel/yellowbook/2012/chapter-3-infectious-diseases-related-to-travel/meningococcal-disease.htm

50. Centers for Disease Control and Prevention. Recommendation of the Advisory Committee on Immunization Practices for Use of Ouadrivalent Meningococcal Conjugate Vaccine (MenACWY-D) Among Children Aged 9 Through 23 Months at Increased Risk for Invasive Meningococcal Disease. MMWR. 2011;60:1391-2.

51. Steffen R. The risk of meningococcal disease in travelers and current recommendations for prevention. J Travel Med. 2010;17:9-17.

52. Ministry of Hajj. Kingdom of Saudi Arabia. Important notices. Visas 2013 [en línea] [consultado el 13/03/2013]. Disponible en www.hajinformation. com/main/t1505.htm

53. World Health Organization. Diseases covered by Global Alert and Response [en línea] [consultado el 13/03/2013]. Disponible en www.who.int/csr/ don/2012_05_24/en/index.html
54. Centers for Disease Control and Prevention. Prevention and control of meningococcal disease: recommendations of the Advisory Committee on Immunization Practices. MMWR. 2005;54(No. RR-7).

55. Ficha técnica de Nimenrix. Glaxosmithkline [en línea] [consultado el 13/03/2013]. Disponible en httwww.ema.europa.eu/docs/es_ES/document_li brary/EPAR___Product_Information/human/ 002226/WC500127663.pdf

56. Hills SL, Nett RJ, Fischer M. Japanese Encephalitis. In: CDC health information for international travel 2012: the yellow book. Atlanta, GA: US Department of Health and Human Services [en línea] [consultado el 10/12/2012]. Disponible en http://wwwnc. cdc.gov/travel/yellowbook/2012/chapter-3-infec tious-diseases-related-to-travel/japanese-encepha litis.htm

57. Ficha técnica de Ixiaro. SBL Vaccin [en línea] [consultado el 13/03/2013]. Disponible en www.ema.europa.eu/docs/en_GB/document_library/EPAR___Pro duct_Information/human/000963/WC500037287. pdf

58. Centers for Disease Control and Prevention. Update on Japanese encephalitis vaccine for children: United States, May 2011. MMWR. 2011;60(20):664-5.

59. Burchard GD, Caumes E, Connor BA, Freedman DO, Jelinek T, Jong EC, et al. Expert opinion on vaccination of travelers against Japanese encephalitis. J Travel Med. 2009;16(3):204-16.

60. Centers for Disease Control and Prevention. Recommendations for use of a booster dose of inactivated vero cell culture-derived Japanese encephalitis vaccine: advisory committee on immunization practices, 2011. MMWR. 2011;60 (20):661-3.

61. Comité de Medicamentos de Uso Humano de la Agencia Europea de Medicamentos sobre la vacuna de la encefalitis japonesa Ixiaro (13/12/2012) [en línea] [consultado el 13/03/2013]. www.ema.euro pa.eu/docs/en_GB/document_library/Summary_ of_opinion/human/000963/WC500 136255.pdf

62. Chotpitayasunondh T, Sohn YM, Yoksan S, Min J, Ohrr H. Immunizing children aged 9 to 15 months with live attenuated SA14-14-2 Japanese encephalitis vaccine in Thailand. J Med Assoc Thai. 2011;94 (3):S195-203. 
63. World Health Organization. Vaccines against tickborne encephalitis: WHO position paper-recommendations. Vaccine. 2011;29:8769-70.

64. Reusken C, Reimerink J, Verduin C, Sabbe L, Cleton N, Koopmans M. Rapid communications. Case report: Tick-borne encephalitis in two Dutch travellers returning from Austria, Netherlands, July and August 2011. Eurosurveill. 2011;16:1-3 [en línea] [consultado el 10/12/2012]. Disponible en www.eurosurvei Ilance.org/ViewArticle.aspx?Articleld=20003

65. Fischer M, Gibney KB, MacNeil A. Tickborne Encephalitis. En: CDC health information for international travel 2012: the yellow book. Atlanta, GA: US Department of Health and Human Services [en línea] [consultado el 10/12/2012]. Disponible en http://wwwnc.cdc.gov/travel/yellowbook/2012/ chapter-3-infectious-diseases-related-to-travel/tickborne-encephalitis.htm

66. Acosta RW. The pre-travel consultation. In: CDC health information for international travel 2012: the yellow book. Atlanta, GA: US Department of Health and Human Services [en línea] [consultado el 10/12/2012]. Disponible en http://wwwnc.cdc. gov/travel/yellowbook/2012/chapter-2-the-pretravel-consultation/the-pre-travel-consultation. htmn

67. Sharapov UM. Hepatitis A. En: CDC health information for international travel 2012: the yellow book. Atlanta, GA: US Department of Health and Human Services [en línea] [consultado el 10/12/2012]. Disponible en http://wwwnc.cdc.gov/travel/yellow book/2012/chapter-3-infectious-diseases-relatedto-travel/hepatitis-a.htm\#2394

68. Infante Pina D, Segarra Cantón O. Hepatopatía aguda. Protocolos diagnóstico-terapéuticos de Gastroenterología, Hepatología y Nutrición Pediátrica. Asociación Española de Pediatría [en línea] [consultado el 10/12/2012]. Disponible en www.aeped.es/ sites/default/files/documentos/hep_aguda.pdf

69. Bui YG, Trépanier S, Milord F, Blackburn M, Provost S, Gagnon S. Cases of malaria, hepatitis A, and typhoid fever among VFRs, Quebec (Canada). J Travel Med. 2011;18(6):373-8

70. Centers for Disease Control and Prevention. Update: Prevention of hepatitis A after exposure to hepatitis $A$ virus and in international travelers. Updated Recommendations of the Advisory Committee on Immunization Practices. MMWR. 2007;56(41):1080-4.
71. Arce Arnáez A, Rodero Garduño I, Iñigo Martínez J, Burgos Arenales M, Guevara Alemany E. Brote de hepatitis $A$ en una escuela infantil y transmisión intrafamiliar de la infección en An Pediatr (Barc). 2004;60:222-7.

72. Ficha técnica de Havrix 720. Glaxosmithkline [en línea] [consultado el 10/12/2012]. Disponible en https://sinaem4.agemed.es/consaem/fichasTecni cas.do? metodo=buscar \&numDefinitivo $=61396$

73. Ficha técnica de Vaqta 25. Sanofi Pasteur [en línea] [consultado el 10/12/2012]. Disponible en https:// sinaem4.agemed.es/consaem/fichasTecnicas.do?m etodo=buscar $\&$ numDefinitivo $=61603$

74. Ficha técnica de Epaxal. Crucell [en línea] [consultado el 10/12/2012]. Disponible en https://sinaem4. agemed.es/consaem/fichasTecnicas.do? metodo $=b$ uscar \&numDefinitivo $=63027$

75. Centers for Disease Control and Prevention. Updated recommendations from the Advisory Committee on Immunization Practices (ACIP) for use of hepatitis A vaccine in close contacts of newly arriving international adoptees. MMWR. 2009;58(36):1006-7.

76. Bhattarai A, Mintz E. Typhoid \& Paratyphoid Fever. In: CDC health information for international travel 2012: the yellow book. Atlanta, GA: US Department of Health and Human Services [en línea] [consultado el 10/12/2012]. Disponible en http://wwwnc. cdc.gov/travel/yellowbook/2012/chapter-3-infec tious-diseases-related-to-travel/typhoid-and-para typhoid-fever.htm

77. Centers for Disease Control and Prevention. Typhoid immunization: recommendations of the Advisory Committee on Immunization Practices. MMWR. 1994;43(RR-14):1-7.

78. Lee Fanning W. TyphimVi Vaccine. J Travel Med. 1997;4:32-7.

79. Ficha técnica de Typherix vi. Glaxosmithkline [en línea] [consultado el 10/12/2012]. Disponible en https://sinaem4.agemed.es/consaem/especialidad. do? metodo=verFichaWordPdf\&codigo $=62710 \&$ for mato $=$ pdf\&formulario $=$ FICHAS

80. Ficha técnica de Typhim Vi. Sanofi Pasteur MSD [en línea] [consultado el 10/12/2012]. Disponible en https://sinaem4.agemed.es/consaem/especialidad. do?metodo=verFichaWordPdf\&codigo $=61509 \&$ for mato=pdf\&formulario=FICHAS 
81. World Health Organization. Typhus vaccine, position paper. Wkly Epidemiol Rec. 2008;83(6):49-59.

82. Arguin PM, Sonja Mali S. Malaria. En: CDC health information for international travel 2012: the yeIlow book. Atlanta, GA: US Department of Health and Human Services [en línea] [consultado el 10/12/ 2012]. Disponible en http://wwwnc.cdc. gov/travel/yellowbook/2012/chapter-3-infectiousdiseases-related-to-travel/malaria.htm

83. Centers for Disease Control and Prevention. Atkinson WL, Pickering LK, Schwartz B, Weniger BG, Iskander JK, Watson JC; General recommendations on immunization. Recommendations of the Advisory Committee on Immunization Practices and the American Academy of Family Physicians. MMWR. 2002; 51(RR-2):1-35.

84. Rupprecht CE, David R. Shlim DR. Rabies. En: CDC health information for international travel 2012: the yellow book. Atlanta, GA: US Department of Health and Human Services [en línea] [consultado el 10/12/2012]. Disponible en http://wwwnc.cdc. gov/travel/yellowbook/2012/chapter-3-infectiousdiseases-related-to-travel/rabies.htm

85. Malerczyk C, Detora L, Gniel D. Imported human rabies cases in Europe, the United States, and Japan, 1990 to 2010. J Travel Med. 2011;18(6):402-7.

86. World Health Organization. Rabies vaccines, position paper. Vaccine. 2010;28:7140-2.

87. Ficha técnica de Rabipur. Novartis [en línea] [consultado el 10/12/2012]. Disponible en https://si naem4.agemed.es/consaem/especialidad.do?meto do=verFichaWordPdf\&codigo $=66100 \&$ formato $=p d$ f\&formulario=FICHAS

88. Date K, Mintz E. Cholera. En: CDC health information for international travel 2012: the yellow book. Atlanta, GA: US Department of Health and Human Services [en línea] [consultado el 10/12/2012]. Disponible en http://wwwnc.cdc.gov/travel/yellow book/2012/chapter-3-infectious-diseases-relatedto-travel/cholera.htm

89. World Health Organization. Cholera vaccines, position paper. Vaccine. 2010;28:4687-8.

90. Clemens JD. Field trial of oral cholera vaccines in Bangladesh: results from three-year follow-up. Lancet. 1990;335:270-3.

91. Ficha técnica de Dukoral. Crucell [en línea] [consultado el 10/12/2012]. Disponible en www.ema.euro-
pa.eu/docs/en_GB/document_library/EPAR___Sum mary_for_the_public/human/000476/WC50 0037569.pdf

92. LoBue P. Tuberculosis. In: CDC health information for international travel 2012: the yellow book. Atlanta, GA: US Department of Health and Human Services [en línea] [consultado el 10/12/2012]. Disponible en http://wwwnc.cdc.gov/travel/yellowbook/2012/ chapter-3-infectious-diseases-related-to-travel/tu berculosis.htm

93. Ficha técnica de BCG $0,75 \mathrm{mg} / \mathrm{ml}$. Pfizer [en línea] [consultado el 10/12/2012]. Disponible en https:// sinaem4.agemed.es/consaem/especialidad.do?met odo=verFichaWordPdf\& $\operatorname{codigo}=40773 \&$ formato $=p$ df\&formulario=FICHAS

94. Organización Mundial de la Salud. Calendarios de Vacunación de todos los países del Mundo [en línea] [consultado el 10/12/2012]. Disponible en http:// apps.who.int/immunization_monitoring/en/glo balsummary/scheduleselect.cfm

95. Alexander JP, Wallace GS, Wassilak SG. Poliomyelitis. En: CDC health information for international travel 2012: the yellow book. Atlanta, GA: US Department of Health and Human Services [en línea] [consultado el 13/03/2013]. Disponible en http://wwwnc. cdc.gov/travel/yellowbook/2012/chapter-3-infec tious-diseases-related-to-travel/poliomyelitis.htm

96. World Health Organization. Polio vaccines and polio immunization in the pre-eradication era. Wkly Epidemiol Rec. 2010;85(23):213-28.

97. Wild Poliovirus 2005-2012. World health organization [en línea] [consultado el 13/03/2013]. Disponible en www.polioeradication.org/Dataandmonito ring.aspx

98. Fiebelkorn AP, Uzicanin A. Measles (Rubeola). En: CDC health information for international travel 2012: the yellow book. Atlanta, GA: US Department of Health and Human Services [en línea] [consultado el 10/12/2012]. Disponible en http://wwwnc. cdc.gov/travel/yellowbook/2012/chapter-3-infec tious-diseases-related-to-travel/measles-rubeola. htm

99. Peña-Rey I, Martínez de Aragón V, Mosquera M, de Ory F, Echevarría JE; Measles Elimination Plan Working Group in Spain. Measles risk groups in Spain: implications for the European measles-elimination target. Vaccine. 2009;27:3927-34. 
100. McCarron M, Shay DK. Influenza (Seasonal, Zoonotic, \& Pandemic). En: CDC health information for international travel 2012: the yellow book. Atlanta, GA: US Department of Health and Human Services [en línea] [consultado el 10/12/2012]. Disponible en http://wwwnc.cdc.gov/travel/yellowbook/2012/ chapter-3-infectious-diseases-related-to-travel/in fluenza-seasonal-zoonotic-and-pandemic.htm

101. World Health Organization. Influenza, position paper [en línea] [consultado el 10/12/2012]. Disponible en www.who.int/immunization/documents/ Influenza_refs_final.pdf

102. Freedman DO, Leder K. Influenza: changing approaches to prevention and treatment in travelers. J Travel Med. 2005;12:36-44.

103. Teshale EH. Hepatitis B. En: CDC health information for international travel 2012: the yellow book. Atlanta, GA: US Department of Health and Human Services [en línea] [consultado el 10/12/2012]. Disponible en http://wwwnc.cdc.gov/travel/yellow book/2012/chapter-3-infectious-diseases-relatedto-travel/hepatitis-b.htm

104. Arguin PM, Mali S. Malaria. En: CDC health information for international travel 2012: the yellow book. Atlanta, GA: US Department of Health and Human Services [en línea] [consultado el 10/12/2012]. Disponible en http://wwwnc.cdc.gov/travel/yellow book/2012/chapter-3-infectious-diseases-relatedto-travel/malaria.htm

105. Weinberg N, Weinberg M, Maloney SA. Traveling Safely with Infants \& Children. En: CDC health information for international travel 2012: the yellow book. Atlanta, GA: US Department of Health and Human Services [en línea] [consultado el 10/12/2012]. Disponible en http://wwwnc.cdc.gov/ travel/yellowbook/2012/chapter-7-internationaltravel-infants-children/traveling-safely-with-in fants-and-children.htm

106. Espinosa-Vega E, Martín-Sánchez AM, Elcuaz-Romano R, Hernández-Febles M, Molina-Cabrillana J, Pérez-Arellano JL. Malaria in paradise: characteriza- tion of imported cases in Gran Canaria Island (1993-2006). J Travel Med. 2011:18:165-72.

107. Venturini E, Chiappini E, Mannelli F, Bonsignori F, Galli L, de Martino M. Malaria prophylaxis in African and Asiatic children traveling to their parents home country: a Florentine Study. J Travel Med. 2011; 18: 161-4.

108. Chen LH, Wilson ME, Schlagenhauf P. Controversies and misconceptions in malaria chemoprophylaxis for travellers. JAMA. 2007;297:2251-63.

109. García López-Hortelano M, Taida García Ascaso M, Mellado Peña MJ, Villota Arrieta J. Patología infecciosa importada I: Malaria. Protocolos de Infectología [en línea] [consultado el 10/12/2012]. Disponible en www.aeped.es/sites/default/files/documen tos/21.pdf

110. Senn N, Rarau P, Stanisic DI, Robinson L, Barnadas C, Manong D, et al. Intermittent Preventive Treatment for Malaria in Papua New Guinean Infants Exposed to Plasmodium falciparum and P. vivax: A Randomized Controlled Trial. PLoS Med. 2012;9(3):e1001195.

111. Sicard S, Simon F, Soula G, Gazin P. Efficacy of antimalarial chemoprophylaxis for travelers. J Travel Med. 2009;16:66-7.

112. Van Rijn SF, Driessen G, Overbosch D, van Genderen PJ. Travel-related morbidity in children: a prospective observational study. J Travel Med. 2012;19(3): 144-9.

113. Herbinger KH, Drerup L, Alberer M, Nothdurft HD, Sonnenburg Fv, Löscher T. Spectrum of imported infectious diseases among children and adolescents returning from the tropics and subtropics. J Travel Med. 2012;19(3):150-7.

114. Hunziker T, Berger C, Staubli G, Tschopp A, Weber R, Nadal D, et al. Profile of travel-associated illness in children, Zürich, Switzerland. J Travel Med. 2012; 19(3):158-62.

115. Fhogartaigh CN, Sanford C, Behrens RH. Preparing young travellers for low resource destinations. BMJ. 2012;6(345):e7179. 